\title{
The involvement of aldosterone in cyclic stretch-mediated activation of NADPH oxidase in vascular smooth muscle cells
}

\author{
Takahiro Ohmine ${ }^{1,2}$, Yoshikazu Miwa ${ }^{1}$, Fumi Takahashi-Yanaga ${ }^{1}$, Sachio Morimoto ${ }^{1}$, Yoshihiko Maehara ${ }^{2}$ \\ and Toshiyuki Sasaguri ${ }^{1}$
}

Increasing evidence suggests that aldosterone is implicated in the pathogenesis of cardiovascular diseases. We examined whether aldosterone contributes to the cyclic stretch (CS)-induced reactive oxygen species (ROS) generation in rat aortic smooth muscle cells (RASMCs). RASMCs were exposed to uniaxial CS and thereafter collected to evaluate the expressions of mRNA or protein relating aldosterone synthesis and the nicotinamide adenine dinucleotide phosphate (NADPH) oxidase activity. CS strength-dependently enhanced NADPH oxidase activity. CS induced cytochrome P450 aldosterone synthase (CYP11B2) and increased aldosterone synthesis but did not influence the levels of $11 \beta$-hydroxysteroid dehydrogenase 2 and mineralocorticoid receptor (MR). This CYP11B2 induction was almost completely suppressed by treatment with an extracellular signal-regulated kinase (ERK) inhibitor, U0126, whereas olmesartan, an angiotensin II (Ang II) receptor blocker (ARB), only partially suppressed CS-induced CYP11B2 expression and ERK phosphorylation. A selective MR antagonist, eplerenone $\left(10 \mu \mathrm{mol}^{-1}\right)$, significantly attenuated the CS-induced NADPH oxidase activation even in the presence of ARBs. In conclusion, aldosterone synthesis, which is partially independent of Ang II, may have an important role in CS-stimulated ROS generation in cultured RASMCs. We also suggest the potential benefit of eplerenone in the treatment of cardiovascular diseases.

Hypertension Research (2009) 32, 690-699; doi:10.1038/hr.2009.76; published online 29 May 2009

Keywords: aldosterone; cyclic stretch; CYP11B2; eplerenone; NADPH oxidase

\section{INTRODUCTION}

Vascular smooth muscle cells (VSMCs) are persistently exposed to pulsatile stretch. Although physiological levels of pulsatile stretch may be required to maintain homeostasis in blood vessels, accumulating evidence has revealed that excessive stretch stimuli associated with hypertension promote atherosclerosis. It has been reported that mechanical stretch stimulates VSMC proliferation ${ }^{1}$ and apoptosis, ${ }^{2}$ and enhances the expression and activity of matrix metalloproteinase 2 , which has a central role in the reorganization of the extracellular matrix. $^{3}$

Reactive oxygen species (ROS) seem to be important mediators in atherogenesis. Increased production of ROS stimulates the oxidation of low-density lipoprotein, ${ }^{4}$ which has a central role in the initiation and development of atherosclerosis. ROS have also been reported to promote atherosclerosis by inducing inflammation, endothelial dysfunction and abnormal VSMC proliferation. ${ }^{5}$ Recent studies have suggested that pulsatile stretch stimulates the generation of ROS through the activation of nicotinamide adenine dinucleotide phosphate (NADPH) oxidase in human VSMCs. ${ }^{3,6}$ Furthermore, it has been revealed that this NADPH oxidase activity is induced mainly through angiotensin II (Ang II), ${ }^{7}$ which evokes local vascular wall inflammation by inducing the production of pro-inflammatory cytokines and chemokines, growth factors and adhesion molecules.

Aldosterone is downstream of Ang II in the renin-angiotensinaldosterone system. Aldosterone has been considered to be synthesized mainly in the adrenal gland and implicated in blood pressure control by regulating renal sodium transport. However, recent studies have suggested that aldosterone is also synthesized in the cardiovascular system and is involved in local tissue injury such as Ang II. Indeed, patients with primary aldosteronism had a higher risk of cardiovascular events than those with essential hypertension. ${ }^{8}$ A pharmacological blockade of aldosterone reduced cardiovascular mortality in patients with congestive heart failure. ${ }^{9}$

Aldosterone is synthesized from corticosterone by cytochrome P450 aldosterone synthase (CYP11B2) and exerts its effect by binding to mineralocorticoid receptor (MR). Although MR has almost the same affinity for glucocorticoids as cortisol and corticosterone, 11ß-hydroxysteroid dehydrogenase $2(11 \beta-H S D 2)$ regulates the selectivity in relation to aldosterone by transforming glucocorticoids into inactivated forms. Recent studies have indicated that CYP11B2 is expressed

${ }^{1}$ Faculty of Medical Sciences, Department of Clinical Pharmacology, Kyushu University, Fukuoka, Japan and ${ }^{2}$ Faculty of Medical Sciences, Department of Surgery and Science, Kyushu University, Fukuoka, Japan

Correspondence: Dr Y Miwa, Faculty of Medical Sciences, Department of Clinical Pharmacology, Kyushu University, Fukuoka, 812-8582, Japan.

E-mail: ymiwa@clipharm.med.kyushu-u.ac.jp

Received 7 September 2008; revised 23 April 2009; accepted 30 April 2009; published online 29 May 2009 
in $\mathrm{VSMCs}^{10}$ and that aldosterone activates NADPH oxidase, ${ }^{11,12}$ suggesting that local aldosterone production in the vascular wall contributes to the generation of ROS and to the subsequent formation of atherosclerotic lesions; however, it has not been investigated whether mechanical stretch influences the production and effect of aldosterone in VSMCs.

Thus, in this study, we investigated the effect of cyclic stretch (CS) on aldosterone synthesis and NADPH oxidase activity in VSMCs. We also tested the effect of eplerenone, a new selective MR antagonist, alone or in combination with Ang II receptor blockers (ARBs), on the CS-induced activation of NADPH.

\section{METHODS}

\section{Chemicals}

Eplerenone, olmesartan and valsartan were kindly supplied by Pfizer Inc. (New York, NY, USA), Sankyo Co. (Tokyo, Japan) and Novartis Pharma KK (Basel, Switzerland), respectively. Spironolactone, SB203580 and 11-deoxycorticosterone acetate were purchased from Sigma-Aldrich (St Louis, MO, USA). U0126 was purchased from Cell Signaling Technology (Beverly, MA, USA). SP600125 was purchased from Biomol Research Laboratories (Plymouth, PA, USA).

\section{Cell culture}

The investigation conforms with the Guide for the Care and Use of Laboratory Animals published by the US National Institutes of Health (NIH publication no. 85-23, revised 1996). Rat aortic smooth muscle cells (RASMCs) isolated from the thoracic aorta of male Sprague-Dawley rats by explants were maintained in growth medium (Dulbecco's modified Eagle's medium (1000 mg glucose/l) (Sigma-Aldrich) containing 10\% fetal bovine serum (Life Technologies, Gaithersburg, MD, USA), $100 \mathrm{U} \mathrm{ml}^{-1}$ penicillin $\mathrm{G}$ and $0.1 \mu \mathrm{g} \mathrm{ml}^{-1}$ streptomycin). RASMCs between passages 3 and 10 were used for experiments after $24 \mathrm{~h}$ of serum starvation.

\section{CS apparatus}

RASMCs $\left(1 \times 10^{6}\right)$ were seeded in a silicon chamber $(32 \mathrm{~mm}$ length, $32 \mathrm{~mm}$ width and $10 \mathrm{~mm}$ depth) pre-coated with $50 \mu \mathrm{g} \mathrm{ml}^{-1}$ bovine plasma fibronectin (Sigma-Aldrich). RASMCs were incubated with growth medium for $24 \mathrm{~h}$ and, thereafter, the medium was replaced with starvation medium (Dulbecco's modified Eagle's medium containing $0.1 \%$ bovine serum albumin). After serum deprivation for $24 \mathrm{~h}$, the medium was again replaced with fresh starvation medium and the cells were exposed to uniaxial CS (5-20\% elongation, $0.5 \mathrm{~Hz}$ ) using NS-750 (Strex, Osaka, Japan), as previously described, ${ }^{13}$ at $37^{\circ} \mathrm{C}$ in a humidified atmosphere of $95 \%$ air $/ 5 \% \mathrm{CO}_{2}$. Control RASMCs (static control) were starved in the same manner as CS cells and were placed in fresh starvation medium before being maintained in an incubator.

\section{Measurement of NADPH oxidase activity}

NADPH oxidase activity was measured by determining the chemiluminescence of lucigenin $\left(5 \mu \mathrm{moll}^{-1}\right.$; Sigma) as previously described, ${ }^{14}$ with minor modifications. Briefly, cells were lysed by sonication and centrifuged for $10 \mathrm{~min}$ at $8000 \mathrm{~g}$. The supernatant was further centrifuged for $1 \mathrm{~h}$ at $100000 \mathrm{~g}$. The pellet was used as the membrane fraction. The membrane protein $(10 \mu \mathrm{g})$ was resuspended in a balanced salt solution of the following composition $\left(\mathrm{mmoll}^{-1}\right)$ : $\mathrm{NaCl}, 128 ; \mathrm{KCl}, 2.5 ; \mathrm{MgSO}_{4}, 1.0 ; \mathrm{CaCl}_{2}, 2.7 ; \mathrm{HEPES}, 20$; glucose, $16 ; \mathrm{pH}$ 7.4. To prevent nonspecific chemiluminescence, $5 \mu \mathrm{l}$ of EGTA $\left(100 \mathrm{mmoll}^{-1}\right)$ and $5 \mu \mathrm{lof} \mathrm{NaN}_{3}\left(100 \mathrm{mmoll}^{-1}\right)$ were added; $5 \mu \mathrm{l}$ of flavin adenine dinucleotide $\left(1 \mathrm{mmoll}^{-1}\right)$ was also added as a substrate, and then $50 \mu \mathrm{l}$ of lucigenin $\left(50 \mu \mathrm{moll}^{-1}\right)$ was added to the cell suspension and incubated at $37^{\circ} \mathrm{C}$ for $5 \mathrm{~min}$ in the dark. Immediately after $25 \mu \mathrm{l}$ of $\beta$-NADPH $\left(10 \mathrm{mmoll}^{-1}\right)$ was added, chemiluminescence was measured using a Luminometer (LB9507, Berthold, Bad Wildbad, Germany). Superoxide dismutase (50 U) (Sigma) was added to stop superoxide production.

\section{Reverse-transcription PCR}

Total cellular RNA was extracted with TRIzol Reagent (Invitrogen, Carlsbad, CA, USA). Reverse-transcription PCR was performed using Ready-To-Go
RT-PCR beads (Amersham-Pharmacia Biotech, Piscataway, NJ, USA) as previously described. ${ }^{15}$ On the basis of the GenBank database, the PCR primers were used as follows: p22, 5'-CATTGCCAGTGTGATCTACC-3' and 5'-ATTA CAGTGGGCATCACC-3'; Nox1, 5'-GGTCAAACAGAGGAGAGCATGA-3' and $5^{\prime}$-CCAGCACAGCCACTTCATAC-3'; Nox2， 5'-GCTGTTCAATGCTTGTGG CT- $3^{\prime}$ and $5^{\prime}$-TCTCCTCATCATGGTGCACA-3'; Nox4, 5'-ATTTTCTCA GGCGTGCATGTGG-3' and $5^{\prime}$-GGAAATGAGCTTGGAACTTGGG-3'; p47 phox, $5^{\prime}$-TACTTCAACAGCCTCATGGGAC- $3^{\prime}$ and $5^{\prime}$-AGTAGCCTGTGACGTCG TCT-3'; p67 ${ }^{\text {phox }}, 5^{\prime}$-CCACTCGAGGATTTGCTTCA-3' ${ }^{\prime}$ and $5^{\prime}$-ATCTTGGAA TGCCTGGGCTC-3' ${ }^{\prime}$; NOXO1, 5'-GCCTGCTACGGAGATCTGA- $3^{\prime}$ and $5^{\prime}$-TT CTCCACCAGCCACCAGCCT-3'; NOXA1， 5'-CACGGTCATCAAAGTTCTA GCC- ${ }^{\prime}$ and $5^{\prime}$-GGAGACTTGAGACAGTAGT- $3^{\prime}$ and GAPDH, $5^{\prime}$-CGGAGTC AACGGATTTGGTCGTAT- $3^{\prime}$ and $5^{\prime}$-AGCCTTCTCCATGGTGGTGAAGAC- $3^{\prime}$. Primers for CYP11B2, 11 $\beta$-HSD2 and MR were designed as previously described. ${ }^{16,17}$ Cycle numbers were 35 for Nox2, p47 phox , p67 phox, NOXO1, NOXA1 and MR, 30 for Nox1, CYP11B2 and 11ß-HSD2, 28 for Nox4 and 24 for GAPDH. Each mRNA level was normalized to that of GAPDH and is given as the fold increase against the basal values.

\section{Western blotting}

Cells were harvested with a Laemmli sample buffer containing $100 \mathrm{mmoll}^{-1}$ dithiothreitol. Total lysate was sonicated and boiled, and thereafter samples ( $10 \mu \mathrm{g}$ per lane) were separated by SDS-PAGE with a $10 \%$ polyacrylamide gel and transferred to a nitrocellulose membrane using a Trans-Blot SD Semi-Dry Transfer Cell (Bio-Rad, Richmond, CA, USA). After blocking with 5\% skim milk for $1 \mathrm{~h}$, the membrane was probed with a primary antibody. Polyclonal antibodies for phosho-ERK1/2 (Cell Signaling Technology), ERK1/2 (Cell Signaling Technology), phosho-JNK1/2 (Cell Signaling Technology), JNK1/2 (Upstate Biotechnology Inc., Lake Placid, NY, USA) and p38 (Santa Cruz Biotechnology Inc., Santa Cruz, CA, USA), and monoclonal antibodies for phosho-p38 (Santa Cruz Biotechnology Inc.) and CYP11B2 (Chemicon, Temecula, CA, USA) and $\beta$-actin (Calbiochem, La Jolla, CA, USA) were used. The membrane was washed three times and incubated with horseradish peroxidase-conjugated anti-rabbit IgG (Cell Signaling Technology) or antimouse IgG (Cell Signaling Technology) for $1 \mathrm{~h}$. Immunoreactive proteins on the membrane were visualized by treatment with a detection reagent (LumiGLO; Cell Signaling Technology). An optical densitometric scan was performed using Science Lab 99 Image Gauge Software (Fuji Photo Film, Tokyo, Japan).

\section{Measurement of aldosterone concentration}

Aldosterone concentrations were measured using an enzyme immunoassay kit (Cayman Chemical Corp., Ann Arbor, MI, USA). After cells were exposed to CS or cultured in static conditions, the culture medium was collected. Cells were collected by scraper and sonicated. The culture medium $(50 \mu \mathrm{l})$ and cellular sample $\left(1 \times 10^{6}\right.$ cells per $\left.50 \mu \mathrm{l}\right)$ were diluted with enzyme immunoassay buffer $(450 \mu \mathrm{l})$ and used directly in the assay according to the manufacturer's instructions.

\section{Cell proliferation assay}

To assess RASMC proliferation, we used the BrdU Cell Proliferation Assay (Exalpha Biologicals Inc., Watertown, MA, USA) according to the manufacturer's protocol. RASMCs were cultured in static condition or were exposed to CS $(10 \%, 0.5 \mathrm{~Hz})$ in the absence or presence of eplerenone $\left(10 \mathrm{mmoll}^{-1}\right)$ for $6 \mathrm{~h}$, and thereafter the cells were incubated overnight in culture medium containing 5-bromo-2-deoxyuridine $\left(2 \mathrm{ml} \mathrm{ml}^{-1}\right)$. The uptake of 5-bromo-2deoxyuridine was determined with a spectrophotometer (Bio-Tek Instruments, Highland Park, VT, USA) and normalized to the amount of cellular protein, which was measured in parallel samples according to the method of Lowry.

\section{Statistics}

Data are expressed as the mean \pm s.d. for three or four independent experiments. Statistical significance among groups was assessed with one-way or two-way analysis of variance. When a significant difference was observed in analysis of variance, the difference between two groups was analyzed by appropriate post hoc analysis. 


\section{RESULTS}

CS increased NADPH oxidase activity and Nox1 mRNA expression First, we examined whether uniaxial CS stimulates NADPH oxidase activity in VSMCs as reported in previous papers. ${ }^{3,6}$ CS $(0.5 \mathrm{~Hz})$ strength-dependently increased NADPH oxidase activity in RASMCs $2 \mathrm{~h}$ after stimulation, although 5\% extension did not influence it (Figure 1a). An extension of more than 20\% impaired cell adhesion and therefore the activity could not be measured. We also examined the effect of CS $(10 \%, 0.5 \mathrm{~Hz})$ on the mRNA expression of NADPH oxidase subunits, that is membrane components Nox1, Nox2, Nox4 and $\mathrm{p} 22^{\text {phox }}$, and cytosol components $\mathrm{p} 47^{\text {phox }}$ and $\mathrm{p} 67^{\text {phox }}$, and their homologs Nox organizer 1 (NOXO1) and Nox activator 1 (NOXA1). In non-stimulated RASMCs, Nox1, Nox4, p22 phox and NOXA1 were clearly detected, although the expression of Nox 2, p $67^{\text {phox }}$ and NOXO1 was undetectable, and the level of p47 phox was very low. CS $(10 \%$, $0.5 \mathrm{~Hz}$ ) significantly increased the mRNA expression of Nox1, whereas that of the other subunits was unaffected (Figure 1b).

CS increased the expression of CYP11B2 and aldosterone production To test whether CS influences the production of aldosterone in VSMCs, we examined the effect of CS on the expression of
CYP11B2, 11 $\beta$-HSD2 and MR, which contribute to the production or effect of aldosterone. CS $(10 \%, 0.5 \mathrm{~Hz})$ significantly increased the CYP11B2 mRNA expression $30 \mathrm{~min}$ after stimulation (Figure 2a), whereas it did not alter the levels of $11 \beta-H S D 2$ and MR. CS (10\%, $0.5 \mathrm{~Hz}$ ) also significantly increased the CYP11B2 protein level; however, the expression level was much lower (11.7 times) in static RASMCs than in the adrenal gland (Figure 2b). This effect was dependent on the strength of the stretch, with a maximal effect being obtained at $15 \%$ (Figure 2c).

To further examine whether CS actually stimulates aldosterone production, we measured the concentration of aldosterone by enzyme immunoassay. Aldosterone concentrations in CS-exposed cells and cell culture medium were below the detected level; however, when measured in the presence of 11-deoxycorticosterone, an aldosterone substrate for CYP11B2, a marked increase in the concentration of aldosterone was observed in the cells (Figure 2d), although aldosterone was still undetectable in the culture medium (data not shown). However, when RASMCs were cultured with a mixture of culture medium and cell lysate obtained from CS-stimulated cells, NADPH oxidase activity was significantly increased when compared with cells cultured with those from static conditioned cells (Figure 2e).

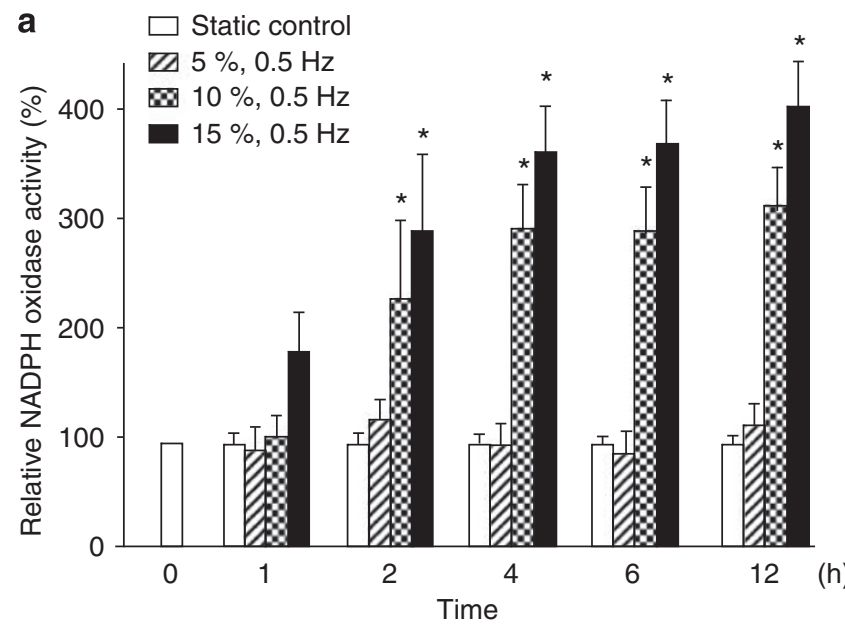

b
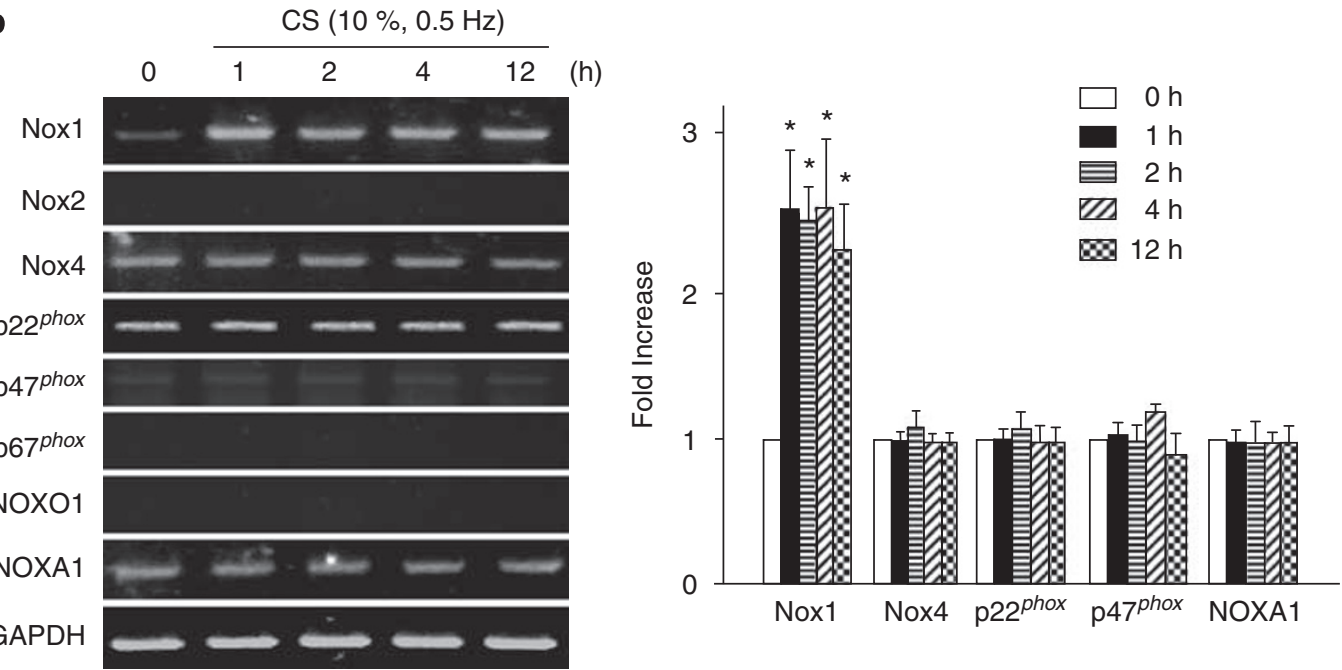

Figure 1 (a) Effect of cyclic stretch (CS) on nicotinamide adenine dinucleotide phosphate (NADPH) oxidase activity. Rat aortic smooth muscle cells (RASMCs) were exposed to CS of various strengths $(0.5 \mathrm{~Hz})$ for the periods indicated. NADPH oxidase activity is given as the fold increase over the value obtained at time 0 . ${ }^{*} P<0.01$ vs. static control at each time. (b) Effect of CS on the expression of NADPH oxidase subunits. RASMCs were exposed to CS ( $10 \%, 0.5 \mathrm{~Hz}$ ) for the periods indicated. The normalized mRNA expression of NADPH oxidase subunits is given as the fold increase over the value obtained at time 0 . ${ }^{*} P<0.01 \mathrm{vs}$. time 0 . 
a
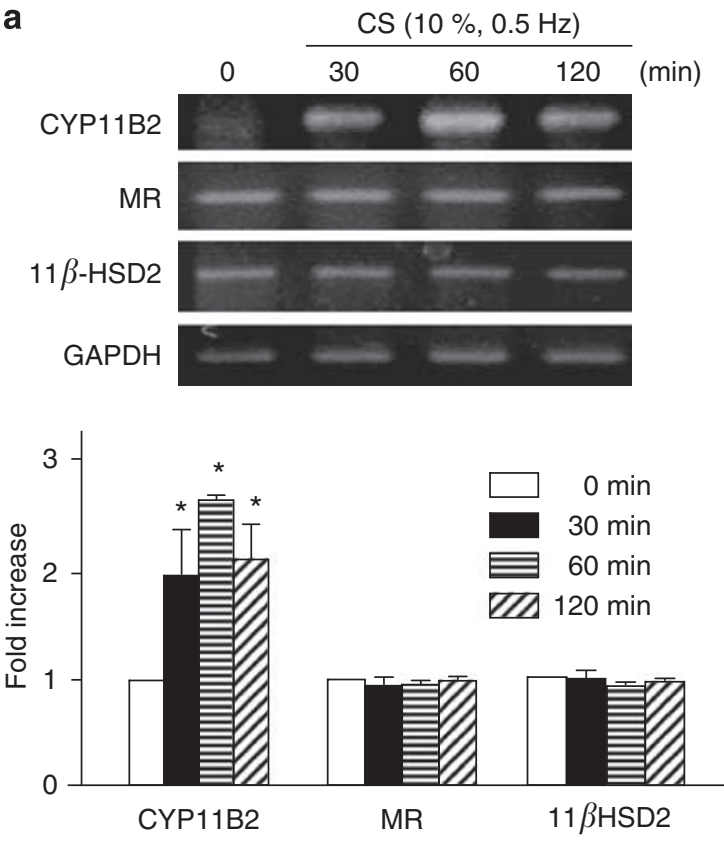

C
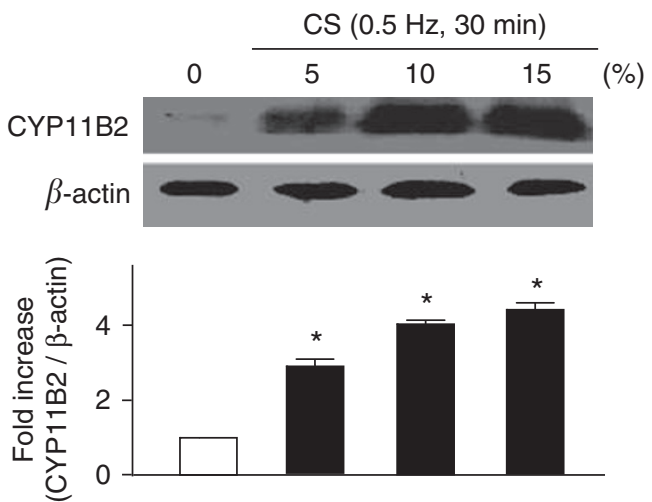

d

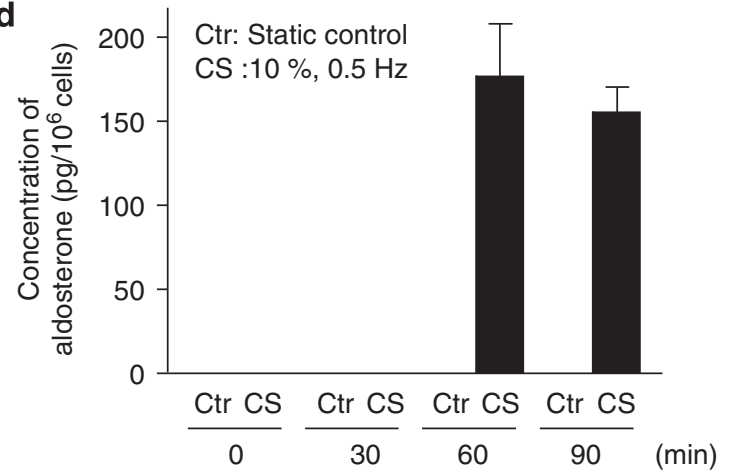

b
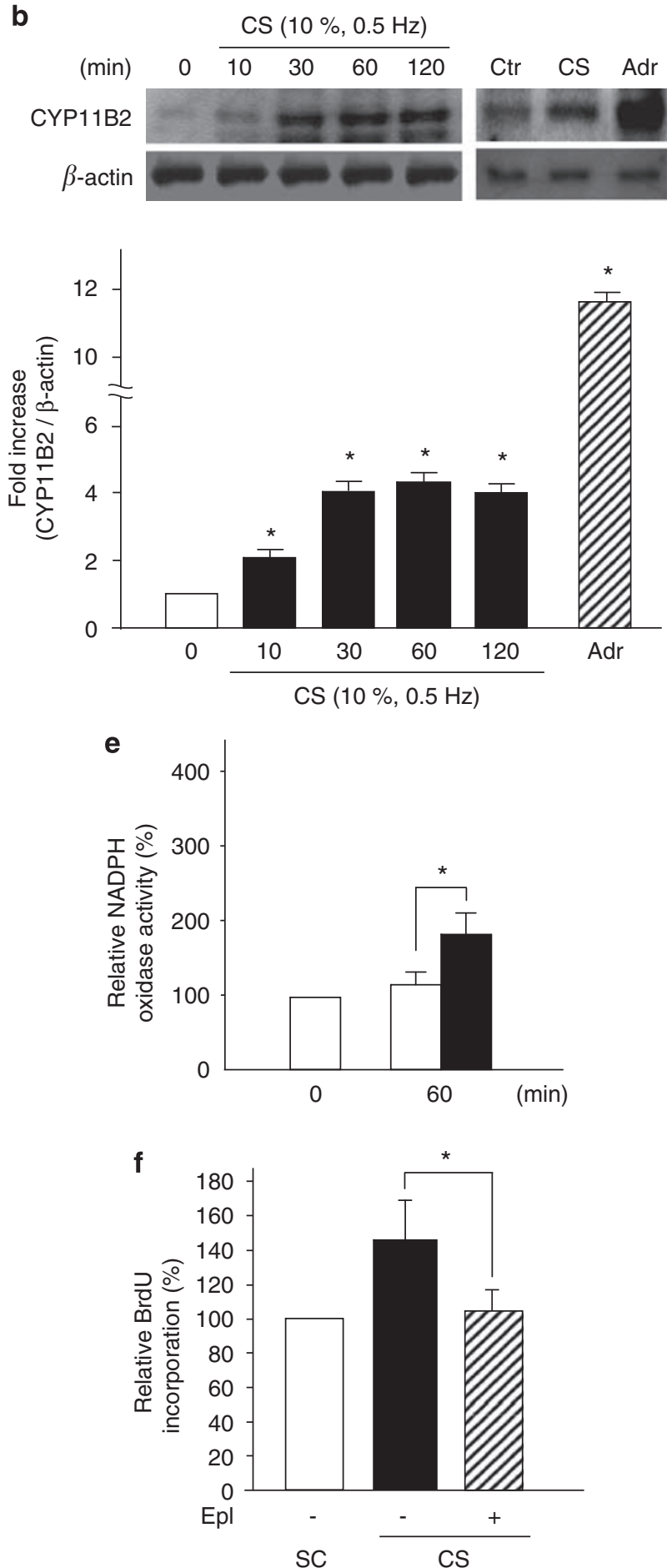

Figure 2 (a) Effects of CS on the mRNA expressions of aldosterone-related proteins. Rat aortic smooth muscle cells (RASMCs) were exposed to cyclic stretch (CS) $(10 \%, 0.5 \mathrm{~Hz})$ for the periods indicated. The normalized mRNA level is given as the fold increase over the value obtained at time $0 .{ }^{*} P<0.01 \mathrm{vs}$. time 0. (b) Effect of CS on the expressions of CYP11B2 protein. Left upper panel: RASMCs were exposed to CS $(10 \%, 0.5 \mathrm{~Hz})$ for the periods indicated. Right upper panel: RASMCs were cultured in static conditions (Ctr) or exposed to CS $(10 \%, 0.5 \mathrm{~Hz})$ for $60 \mathrm{~min}$. Adrenal gland (Adr) was obtained from SpragueDawley rats. The normalized expression of CYP11B2 protein is given as the fold increase over the value obtained at time 0 . ${ }^{*} P<0.01$ vs. time 0 . (c) Strength dependency of the induction of CYP11B2 by CS. RASMCs were exposed to the indicated strengths of CS for $30 \mathrm{~min}$. ${ }^{*} P<0.01 \mathrm{vs}$. $0 \%$. (d) Secretion of aldosterone by CS in the presence of substrate. RASMCs were cultured in static conditions (Ctr) or exposed to CS ( $10 \%, 0.5 \mathrm{~Hz})$ in the presence of 11-deoxycorticosterone for the periods indicated. The aldosterone concentration in cells was determined as described in Methods and was shown as pg per $10^{6}$ cells. (e) Activation of nicotinamide adenine dinucleotide phosphate (NADPH) oxidase by a mixture of culture medium and cell lysate obtained from CS-stimulated cells. RASMCs were cultured at the indicated times in mixtures of cultured medium and cell lysates obtained from static cells (open bar) or CS-stimulated cells (closed bar), respectively. NADPH oxidase activity is given as the fold increase over the value obtained at time $0 .{ }^{*} P<0.01$. (f) Effects of eplerenone on CS-induced increase in DNA synthesis. After serum starvation for $24 \mathrm{~h}$, RASMCs were immediately exposed to CS ( $10 \%$, $0.5 \mathrm{~Hz})$ for $6 \mathrm{~h}$ in the absence or presence of $\mathrm{Epl}\left(10 \mu \mathrm{mol} \mathrm{I}^{-1}\right)$ and thereafter incubated with 5-bromo-2-deoxyuridine (BrdU). BrdU incorporation was measured and analyzed as described in Methods. The data are presented as values relative to the static control (SC) in the bar graph. ${ }^{*} P<0.05$. 
As aldosterone exerts its hormonal effects through binding to MR, we subsequently examined whether antagonizing MR is able to suppress CS-induced cellular responses. As shown in Figure 2f, exposure to CS for $6 \mathrm{~h}$ significantly increased RASMC proliferation evaluated by 5-bromo-2-deoxyuridine incorporation compared with control (static) cells and, furthermore, a selective MR antagonist, eplerenone $\left(10 \mu \mathrm{moll}^{-1}\right)$, significantly suppressed CS-induced cell proliferation. These results indicate the possibility that a very small amount of aldosterone induced by CS stimulates NADPH oxidase activation and subsequent cellular responses in RASMCs.

\section{Involvement of ERK in CS-induced CYP11B2 expression}

The above results suggest that CS stimulates aldosterone synthesis by inducing CYP11B2 expression in RASMCs. Several recent reports have suggested that mitogen-activated protein kinases (MAPKs), such as extracellular signal-regulated kinase (ERK), c-Jun N-terminal

a
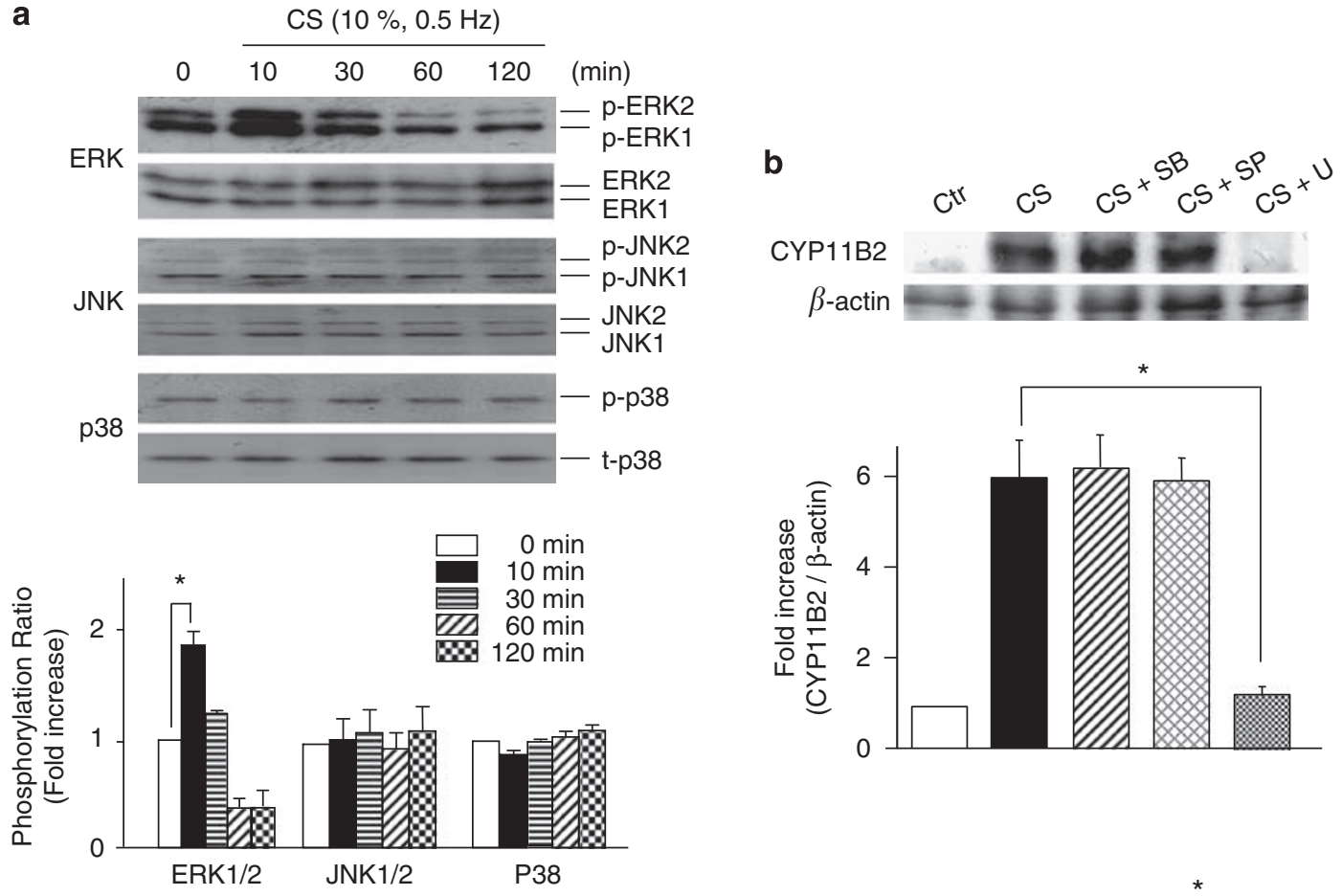

C $\begin{array}{rlll}\mathrm{CS}(10 \%, 0.5 \mathrm{~Hz}) & 0 & \frac{30}{-}+\frac{60}{-}+(\min .)\end{array}$
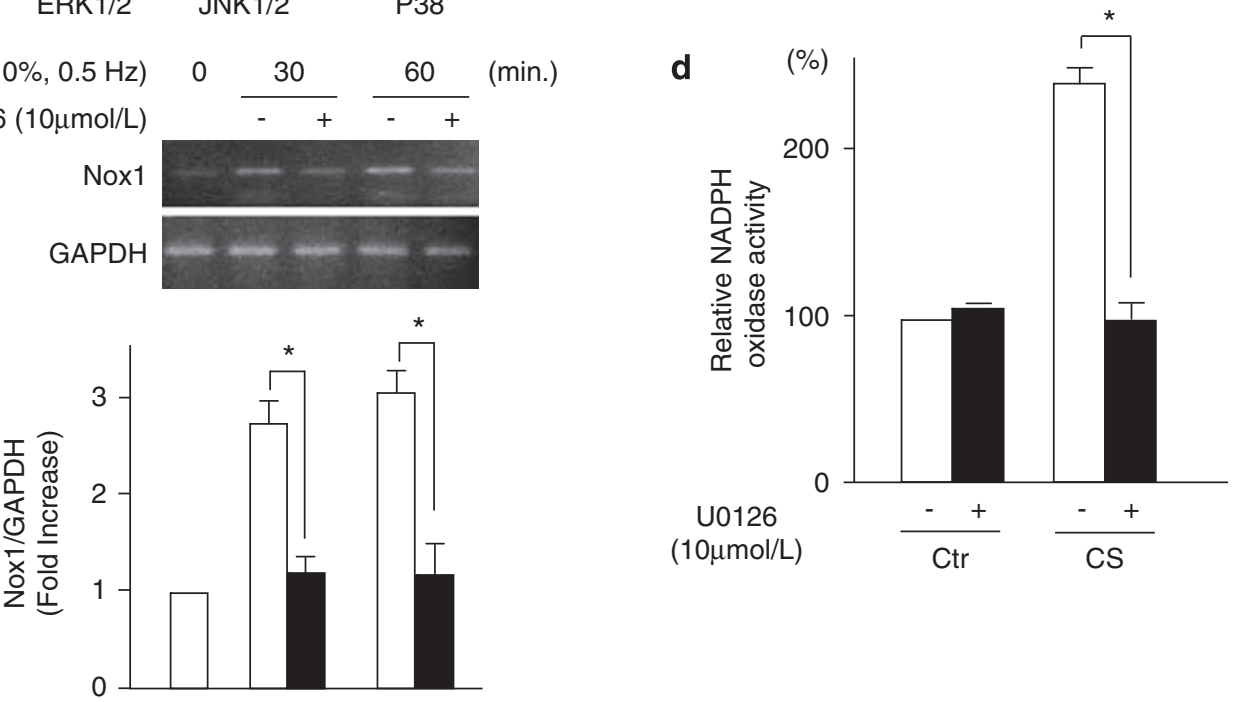

Figure 3 (a) Effect of cyclic stretch (CS) on the phosphorylation of mitogen-activated protein kinases (MAPKs). Rat aortic smooth muscle cells (RASMCs) were exposed to CS $(10 \%, 0.5 \mathrm{~Hz})$ for the periods indicated. The phosphorylation ratio of MAPKs is shown as the fold increase over the value obtained at time 0. ${ }^{*} P<0.01$. (b) Effect of MAPK inhibitors on CS-induced CYP11B2 expression. RASMCs were exposed to CS $(10 \%, 0.5 \mathrm{~Hz})$ for $30 \mathrm{~min}$ with $0.1 \%$ dimethyl sulfoxide (CS), $10 \mu \mathrm{mol} \mathrm{I}^{-1}$ of the p38 inhibitor SB203580 (CS+SB), $10 \mu \mathrm{mol} \mathrm{I}^{-1}$ of the JNK inhibitor SP600125 (CS+SP) and $10 \mu \mathrm{mol} \mathrm{I}^{-1}$ of the ERK inhibitor U0126 (CS+U). Control cells (Ctr) were placed under static conditions in an incubator for 30 min. The normalized protein expression of CYP11B2 is given as the fold increase over the value obtained from Ctr. ${ }^{*} P<0.01$. (c) Effect of U0126 on the expression of CS-induced Nox1 mRNA. RASMCs were exposed to CS $(10 \%, 0.5 \mathrm{~Hz})$ in the presence or absence of $\mathrm{U} 0126\left(10 \mu \mathrm{moll}^{-1}\right)$ for the periods indicated. The normalized mRNA level of Nox 1 is given as the fold increase over the value obtained at time $0 .{ }^{*} P<0.01$. (d) Effect of U0126 on CS-induced nicotinamide adenine dinucleotide phosphate (NADPH) oxidase activity. RASMCs were exposed to CS $(10 \%, 0.5 \mathrm{~Hz})$ for $2 \mathrm{~h}$ in the presence or absence of U0126. NADPH oxidase activity is shown as the fold increase over the value obtained from the static control (Ctr) without U0126. ${ }^{*} P<0.01$. 
kinase (JNK) and p38, are activated by CS in VSMCs ${ }^{18-20}$ and also contribute to CYP11B2 expression. ${ }^{21,22}$ Therefore, we subsequently investigated whether MAPKs are involved in CS-induced CYP11B2 expression. CS $(10 \%, 0.5 \mathrm{~Hz})$ transiently activated ERK; however, the activation of JNK and p38 was not altered (Figure 3a). Pre-treatment with the ERK1/2 inhibitor, U0126, almost completely suppressed CS-induced CYP11B2 expression (Figure 3b), whereas, by contrast, a p38 inhibitor, SB203580, and a JNK1/2 inhibitor, SP600125, did not affect the expression. U0126 also suppressed the CS-induced expression of Nox1 (Figure 3c) and NADPH oxidase activity (Figure 3d), suggesting that ERK has a key role in the expression of CYP11B2 induced by CS.

\section{Aldosterone increased NADPH oxidase activity}

To confirm the effect of aldosterone on NADPH oxidase activity, RASMCs were treated with exogenous aldosterone $\left(100 \mathrm{nmoll}^{-1}\right)$. Aldosterone significantly increased both Nox1 mRNA expression and NADPH oxidase activity (Figures $4 \mathrm{a}$ and $\mathrm{b}$ ). We subsequently examined whether antagonizing $\mathrm{MR}$ is able to suppress aldosteroneinduced NADPH oxidase activity. When we treated RASMCs with eplerenone $\left(10 \mu \mathrm{moll}^{-1}\right)$, aldosterone-induced increases in Nox 1 expression and NADPH oxidase activity were strongly suppressed (Figures $4 \mathrm{c}$ and $\mathrm{d}$ ), suggesting that aldosterone stimulates NADPH oxidase activity mainly through MR. By contrast, eplerenone did not affect the CS-induced CYP11B2 expression and ERK phosphorylation (data not shown).

a

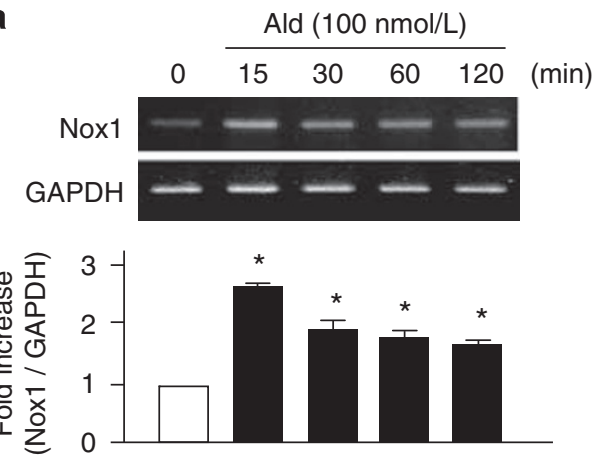

c

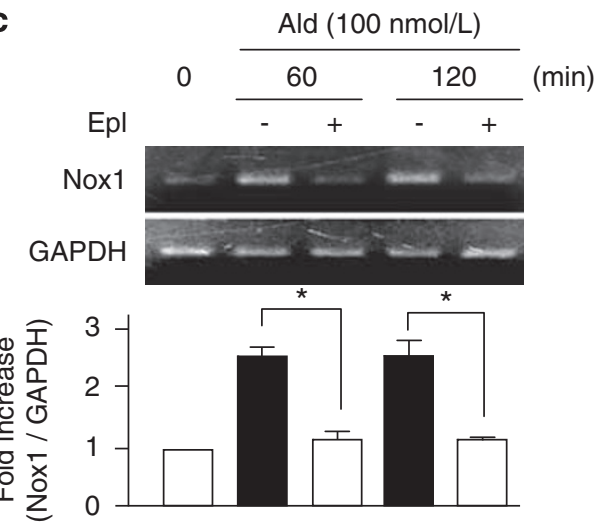

ARB inhibited CS-induced CYP11B2 expression and NADPH oxidase activity

Ang II is a major stimulator of aldosterone synthesis that has also been reported to have an important role in NADPH oxidase activity. To determine whether Ang II is involved in the CS-mediated production of aldosterone and activation of NADPH oxidase, we examined the effect of an ARB, olmesartan. Ang II $\left(100 \mathrm{nmoll}^{-1}\right)$ increased the ERK phosphorylation (Figure 5a) and Nox 1 expression (Figure 5b) in RASMCs. Ang II also induced CYP11B2 expression, although the effect was relatively small (Figure 5c). U0126 almost completely suppressed the Ang II-induced expression of Nox 1 and CYP11B2 (Figures $5 \mathrm{~b}$ and $\mathrm{c}$ ).

In RASMCs exposed to Ang II, olmesartan at concentrations of $10 \mathrm{nmol}^{-1}$ and above almost completely suppressed Ang II-stimulated NADPH oxidase activity (Figure 5d). Pre-treatment with $100 \mathrm{nmoll}^{-1}$ of olmesartan significantly, but not completely, suppressed CS-induced CYP11B2 expression (Figure 5e). As shown in Figure 5f, olmesartan significantly but not completely suppressed the CS-induced ERK1/2 phosphorylation, suggesting that CS-induced CYP11B2 expression through the activation of ERK is partially dependent on Ang II, although other Ang II-independent pathways may also exist.

\section{Additive effects of aldosterone on Ang II-induced ERK} phosphorylation, Nox1 expression and NADPH oxidase activity We further examined whether aldosterone has additive effects on ERK phosphorylation, Nox1 expression and NADPH oxidase activity when

b

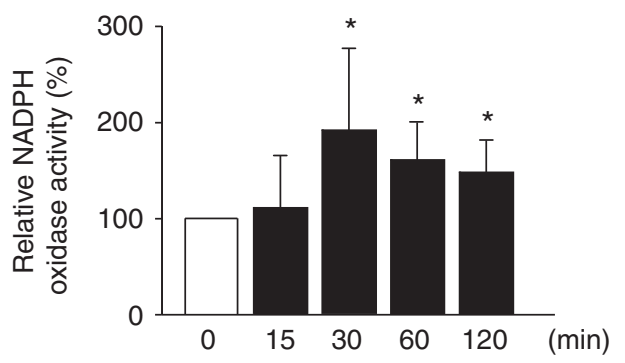

d

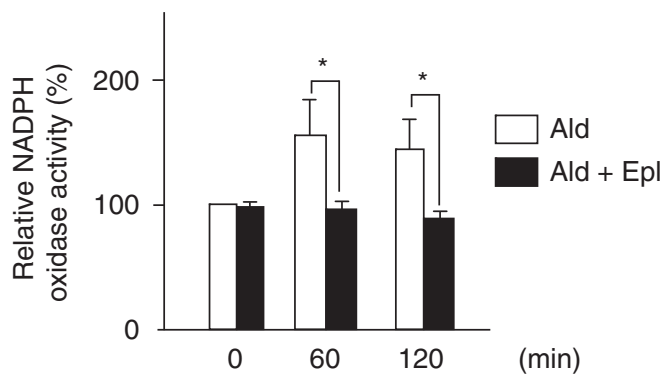

Figure 4 (a) Effect of aldosterone on the expression of Nox 1 mRNA. Rat aortic smooth muscle cells (RASMCs) were treated with $100 \mathrm{nmol} \mathrm{I}^{-1}$ aldosterone (Ald) at the indicated times. The normalized mRNA level of Nox1 is given as the fold increase over the value obtained at time 0 . ${ }^{*} P<0.01$ vs. time 0 . (b) Effect of aldosterone on the nicotinamide adenine dinucleotide phosphate (NADPH) oxidase activity. RASMCs were treated as described in (a). NADPH oxidase activity is presented as the fold increase over the value obtained at time 0 . ${ }^{*} P<0.01$ vs. time 0 . (c) Effect of eplerenone (Epl) on Ald-induced Nox 1 expression. RASMCs were stimulated with Ald $\left(100 \mathrm{nmoll}^{-1}\right)$ in the absence or presence of Epl $\left(20 \mu \mathrm{moll} \mathrm{I}^{-1}\right)$ for the periods indicated. The normalized mRNA level of Nox1 is given as the fold increase over the value obtained at time 0 . ${ }^{*} P<0.01$ vs. time 0 . (d) Effect of Epl- on Ald-induced NADPH oxidase activity. RASMCs were treated as described in (c). NADPH oxidase activity is presented as the fold increase over the value obtained at time $0 .{ }^{*} P<0.01$. 


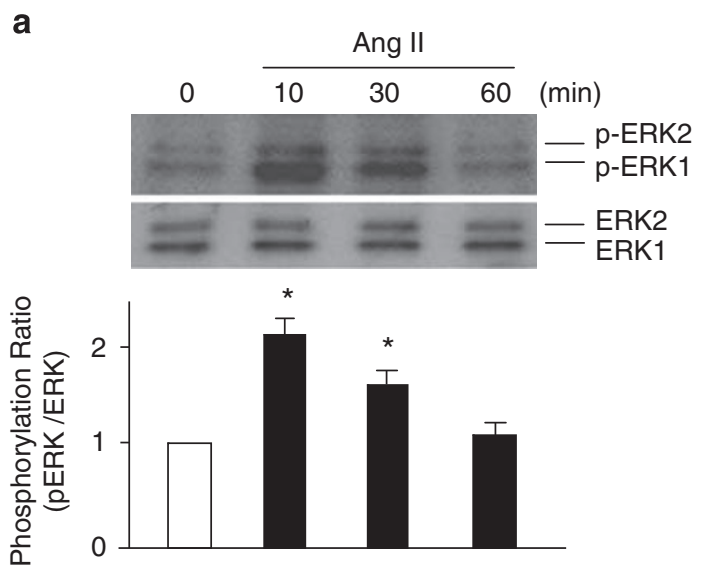

b
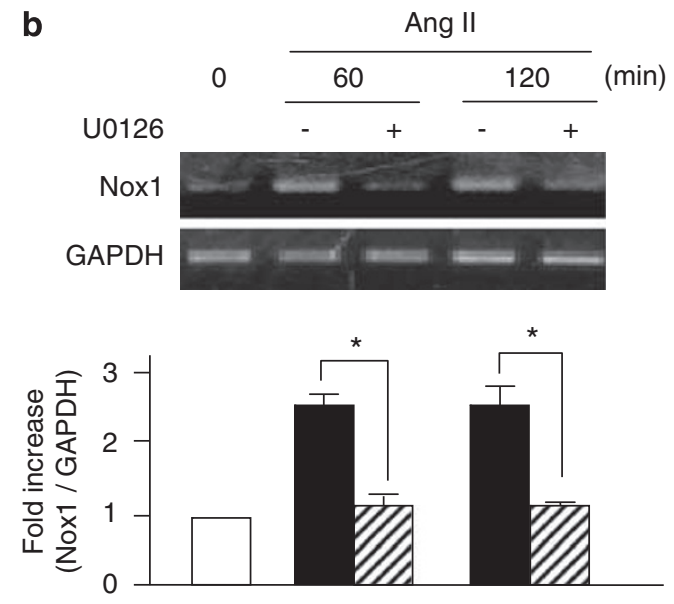
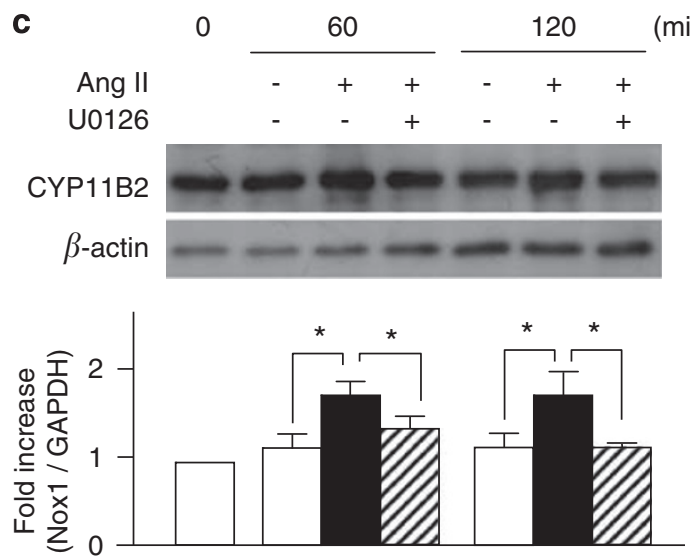

e
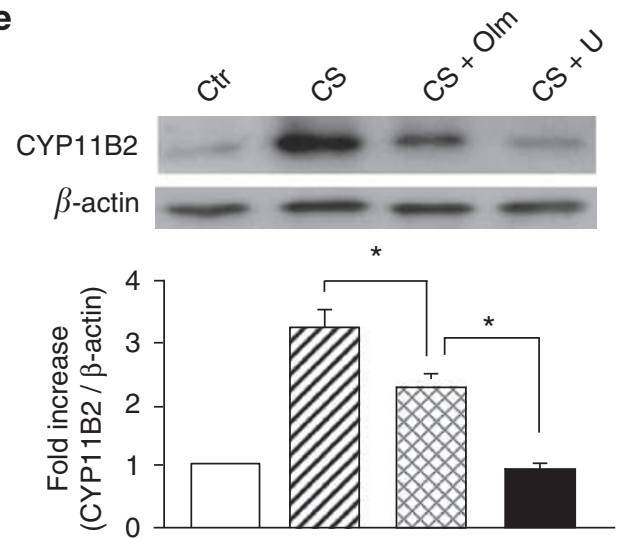

d

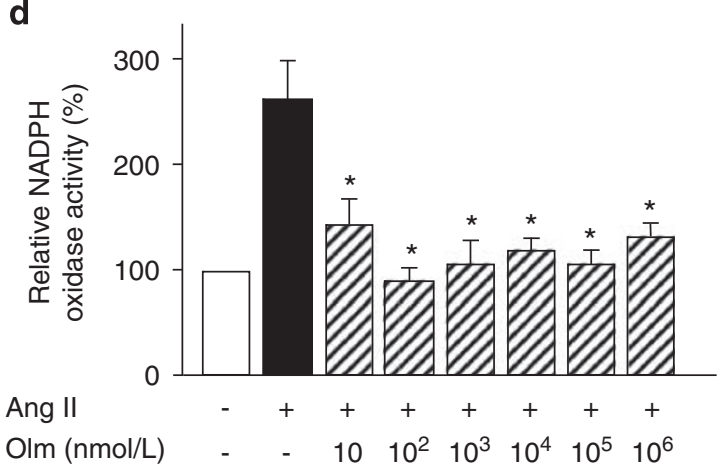

f

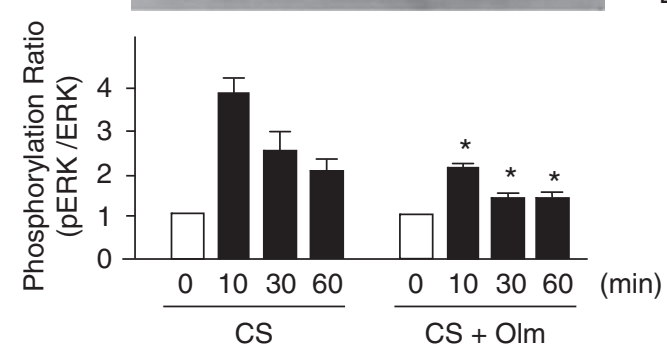

Figure 5 (a) Effect of angiotensin II (Ang II) $\left(100 \mathrm{nmol} \mathrm{I}^{-1}\right)$ on ERK1/2 phosphorylation. The phosphorylation ratio is shown as described in Figure 3 a. ${ }^{*} P<0.01$ vs. time 0 . (b) Effect of U0126 on Ang II-induced Nox1 expression. Rat aortic smooth muscle cells (RASMCs) were stimulated with Ang II $\left(100 \mathrm{nmol} \mathrm{I}^{-1}\right)$ in the presence or absence of $\mathrm{U} 0126\left(10 \mu \mathrm{moll}^{-1}\right)$. The normalized expression of Nox1 mRNA is presented as the fold increase over the value obtained at time $0 .{ }^{*} P<0.01$. (c) Effect of U0126 on Ang II-induced CYP11B2 expression. RASMCs were treated as described in (b). The normalized expression of CYP11B2 is presented as the fold increase over the value obtained at time 0 . ${ }^{*} P<0.05$. (d) Effect of olmesartan (OIm) on Ang II-induced nicotinamide adenine dinucleotide phosphate (NADPH) oxidase activity. RASMCs were stimulated with Ang II $\left(100 \mathrm{nmol}^{-1}\right)$ in the presence of the indicated concentrations of Olm. NADPH oxidase activity is presented as the fold increase over the value obtained from static control cells (open bar). ${ }^{*} P<0.01 \mathrm{vs}$. Ang II-stimulated cells without OIm (closed bar). (e) Effect of OIm on cyclic stretch (CS)-induced CYP11B2 expression. RASMCs were exposed to CS (10\%, $0.5 \mathrm{~Hz}$ ) in the presence of $100 \mathrm{nmol} \mathrm{I}^{-1}$ of $\mathrm{Olm}(\mathrm{CS}+\mathrm{Olm})$ or $10 \mu \mathrm{mol} \mathrm{I}^{-1}$ of $\mathrm{U0126}(\mathrm{CS}+\mathrm{U})$. The normalized CYP11B2 expression is given as the fold increase over the value obtained from static control cells (Ctr). ${ }^{*} P<0.01$. (f) Effect of olmesartan (OIm) on CS-induced ERK phosphorylation. RASMCs were exposed to CS $(10 \%, 0.5 \mathrm{~Hz})$ in the absence or presence of $\mathrm{Olm}\left(100 \mathrm{nmol} \mathrm{I}^{-1}\right)$ for the periods indicated. The phosphorylation ratio is shown as described in Figure 3 a. ${ }^{*} P<0.01$ vs. $C S$ at each time. 
a

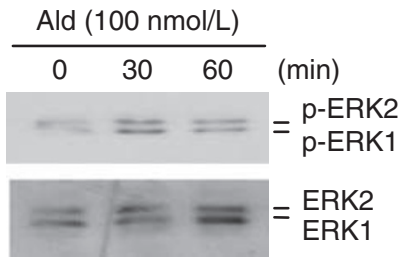

b
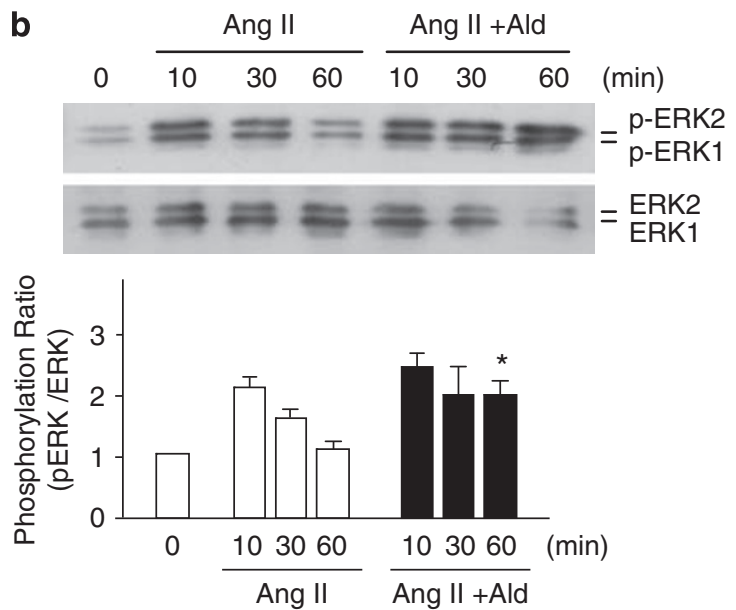

C

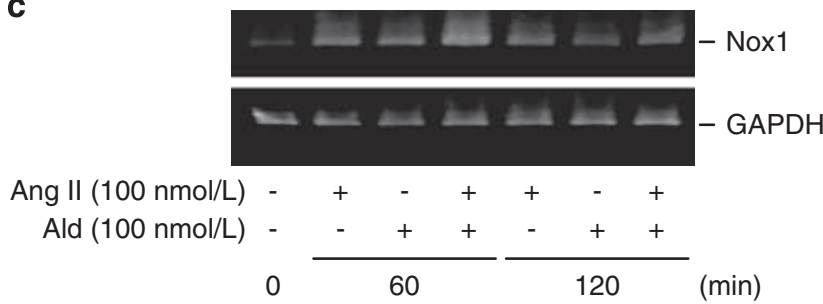

d

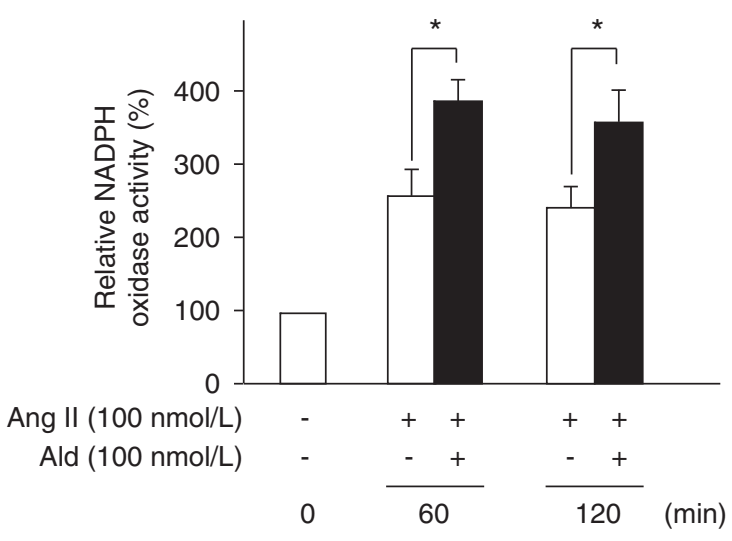

Figure 6 (a) Effect of aldosterone (Ald, $100 \mathrm{nmolI}^{-1}$ ) on ERK1/2 phosphorylation. (b) Additional effect of Ald (100 nmol $\mathrm{I}^{-1}$ ) on ERK1/2 phosphorylation when co-treated with angiotensin II (Ang II). The phosphorylation ratio is shown as described in Figure 3 a. ${ }^{*} P<0.01$ vs. Ang II alone. (c) Additional effect of Ald $\left(100 \mathrm{nmol}^{-1}\right)$ on Nox1 expression when co-treated with Ang II. Rat aortic smooth muscle cells (RASMCs) were treated with Ang II (100 nmol I-1), Ald $\left(100 \mathrm{nmolI}^{-1}\right)$ or both for the indicated times. (d) Additional effect of Ald on NADPH oxidase activity when co-treated with Ang II. RASMCs were treated with Ang II $\left(100 \mathrm{nmolI}^{-1}\right)$ or Ang II+Ald $\left(100 \mathrm{nmolI}^{-1}\right)$ for the indicated times. NADPH oxidase activity is presented as the fold increase over the value obtained from static control cells at time $0 .{ }^{*} P<0.01$.

cells were co-treated with Ang II. Aldosterone $\left(100 \mathrm{nmoll}^{-1}\right)$ significantly increased ERK phosphorylation in RASMCs (Figure 6a). When co-treated with Ang II $\left(100 \mathrm{nmoll}^{-1}\right)$, ERK phosphorylation tended to increase at 10 and $30 \mathrm{~min}$ after stimulation, but was not significant statistically. However, $60 \mathrm{~min}$ after stimulation, it significantly increased in RASMC co-treated with Ang II and aldosterone compared with Ang II alone (Figure 6b). The Nox1 expression (Figure 6c) and NADPH oxidase activation (Figure $6 \mathrm{~d}$ ) were also enhanced by cotreatment with aldosterone compared with Ang II alone.

\section{MR antagonists inhibited CS-induced NADPH oxidase activity}

We examined whether CS-induced production of aldosterone contributes to NADPH oxidase activity using MR antagonists. Both eplerenone and spironolactone attenuated the CS-induced activity (Figures 7a and b). Similarly, Nox1 mRNA expression induced by CS was suppressed by eplerenone (Figure $7 \mathrm{c}$ ).

We also examined the effect of co-treatment with eplerenone and ARBs on CS-induced NADPH oxidase activity. Olmesartan and valsartan suppressed the CS-induced activity to a similar extent as eplerenone; however, co-treatment with eplerenone had an additive suppressive effect on ARBs (Figure 7d).

\section{DISCUSSION}

In this study, we showed for the first time that CS increased the expression of CYP11B2 in VSMCs. Although the levels of CYP11B2 were much lower in VSMCs than in the adrenal gland and CS could not increase the concentration of aldosterone above the level detect- able by enzyme immunoassay, a marked increase in aldosterone concentrations was observed in CS-exposed cells in the presence of the substrate of aldosterone, 11-deoxycorticosterone. CS as well as exogenous aldosterone enhanced NADPH oxidase activity, which has an important role in ROS production in the vascular wall and, furthermore, the MR antagonists, spironolactone and eplerenone, significantly suppressed the CS-induced increase in NADPH oxidase activity. These results suggest that local aldosterone synthesis by CS contributes to the activation of NADPH oxidase through MR in VSMCs. Although the role of locally produced aldosterone in the vascular wall is controversial because of its small quantity, recent reports have indicated that vascular aldosterone potentiates Ang IIinduced hypertrophy ${ }^{10}$ or proliferation ${ }^{23}$ of cultured VSMCs. The CS-induced upregulation of CYP11B2 expression and the inhibitory effects of the MR antagonist on CS-induced NADPH oxidase activity shown in this study suggest that a locally produced but very small amount of aldosterone contributes to CS-induced NADPH oxidation in the vascular wall.

NADPH oxidase is a multisubunit complex consisting of membrane-bound and cytosolic components, and in VSMCs, the expression of p22 $2^{\text {phox }}$, Nox1, Nox2 (gp91 ${ }^{\text {phox }}$ ), Nox4 (membrane-bound components) and p47phox6 (cytosolic components) has been reported. ${ }^{24}$ In our RASMCs, the expression of Nox2 and p47phox was undetectable or quite low as previously described. ${ }^{25-27} \mathrm{CS}$ significantly increased the expression of Noxl but not of the other subunits. Although several different mechanisms were proposed regarding the regulation of $\mathrm{NADPH}$ oxidase activity in VSMCs, 

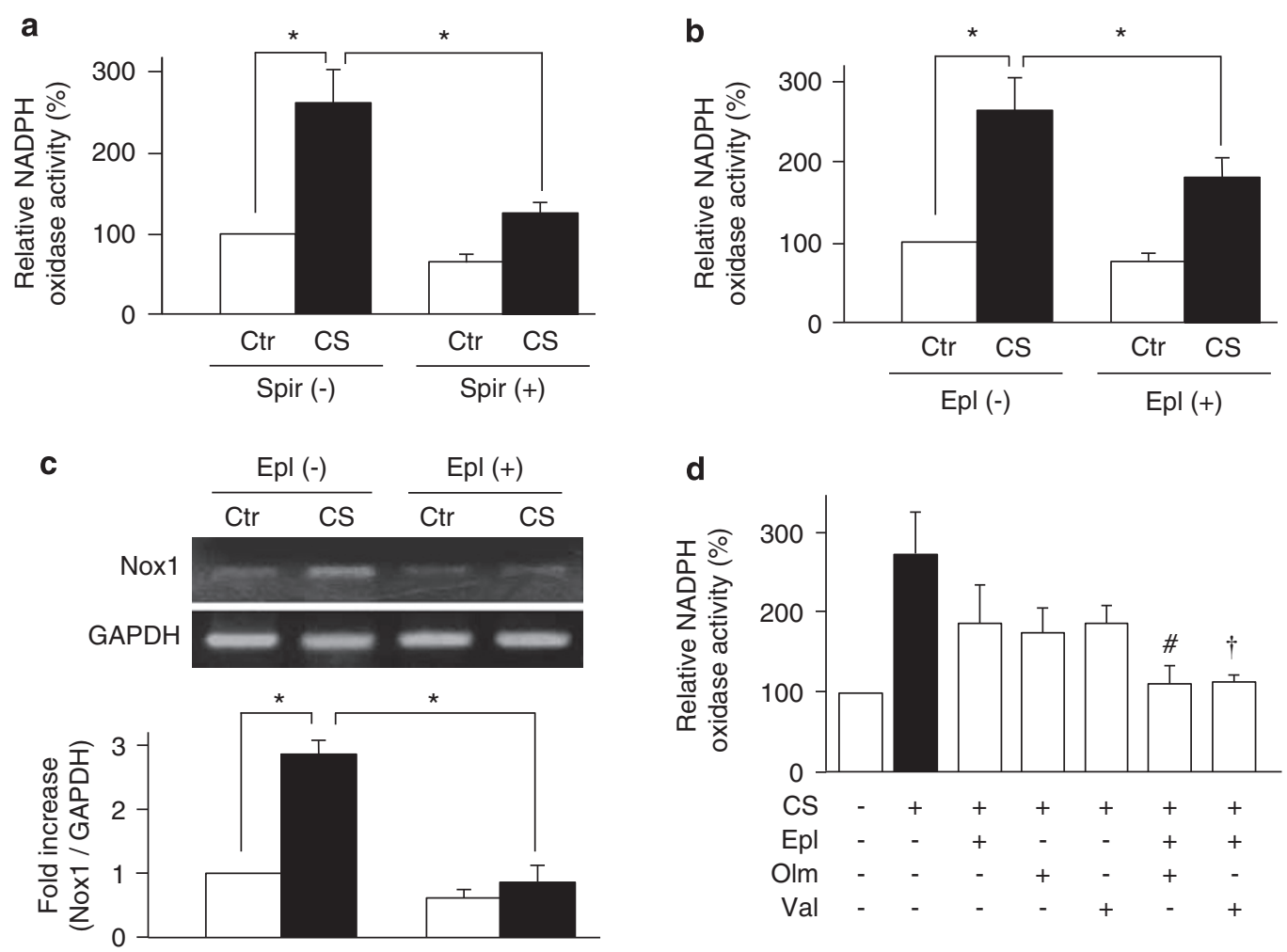

Figure 7 (a) Effect of spironolactone (Spir) on cyclic stretch (CS)-induced nicotinamide adenine dinucleotide phosphate (NADPH) oxidase activity. Rat aortic smooth muscle cells (RASMCs) were exposed to CS $(10 \%, 0.5 \mathrm{~Hz})$ for $2 \mathrm{~h}$ in the absence or presence of Spir $\left(20 \mu \mathrm{mol} \mathrm{I}^{-1}\right)$. NADPH oxidase activity is presented as the fold increase over the value obtained from static control cells (Ctr) in the absence of Spir. ${ }^{*} P<0.01$. (b) Effect of eplerenone (Epl) on CS-induced NADPH oxidase activity. RASMCs were exposed to CS $(10 \%, 0.5 \mathrm{~Hz})$ for $2 \mathrm{~h}$ in the absence or presence of Epl $\left(10 \mu \mathrm{mol} \mathrm{I}^{-1}\right)$. NADPH oxidase activity is presented as the fold increase over the value obtained from static control cells (Ctr) in the absence of Epl. ${ }^{*} P<0.01$. (c) Effect of Epl on CS-induced Nox1 expression. RASMCs were maintained as described in (a). The normalized mRNA level is given as the fold increase over the values obtained from the static control cells (Ctr) without Epl. ${ }^{*} P<0.01$. (d) Synergistic effects of olmesartan $(\mathrm{Olm})$ and valsartan (Val) with eplerenone (Epl) on CS-induced NADPH oxidase activity. RASMCs were exposed to CS $(10 \%, 0.5 \mathrm{~Hz})$ for $2 \mathrm{~h}$ in the presence of Epl $\left(10 \mu \mathrm{mol} \mathrm{I} \mathrm{I}^{-1}\right)$ and/or $0 \mathrm{~lm}\left(100 \mathrm{nmol} \mathrm{I}^{-1}\right)$ and Val $\left(100 \mathrm{nmol}^{-1}\right)$. NADPH oxidase activity is presented as the fold increase over the value obtained from static control cells $(C t r) .{ }^{*} P<0.05$ vs. CS. ${ }^{\#} P<0.01$ vs. Olm alone. ${ }^{\dagger} P<0.01$ vs. Val alone.

Nox1 is the only subunit of NADPH oxidase whose expression is reported to be inducible by various stimuli, such as Ang II, serum, platelet-derived growth factor ${ }^{24}$ and prostaglandin $\mathrm{F}_{2 \alpha}{ }^{28}$ Our data suggest that CS stimulates NADPH oxidase activity by inducing the expression of Nox1.

Recent reports suggest that mitogen-activated protein kinases contribute to aldosterone production. ${ }^{18,19}$ Our results show that the phosphorylation of ERK1/2, but not of JNK or p38, is enhanced by CS. The ERK inhibitor, U0126, almost completely suppressed the CS-induced expression of CYP11B2, indicating that CS induces expression through the phosphorylation of ERK1/2. We also show that Ang II enhanced ERK1/2 phosphorylation, NADPH oxidase activity and Noxl expression in RASMCs as well as CS. Ang II also increased CYP11B2 expression in RASMCs, although the effect was relatively small (Figure $5 \mathrm{c}$ ). However, olmesartan could only partially suppress CS-induced ERK1/2 phosphorylation and CYP11B2 expression, whereas the effect of U0126 was almost complete. Therefore, the CS-mediated expression of CYP11B2 induced through the phosphorylation of ERK1/2 seemed to be partially mediated by Ang II, but Ang II-independent pathways may also exist. Although the mechanism remains unclear, Ang II-independent aldosterone production has been suggested. In half of the patients with essential hypertension treated with angiotensin-converting enzyme inhibitors, despite sufficient suppression of the plasma Ang II concentration, aldosterone secretion was not suppressed, ${ }^{29}$ a phenomenon usually called the 'aldosterone breakthrough.' In hypertensive rats, an aldosterone antagonist has been shown to facilitate the cardioprotective effects of angiotensin receptor blockers. ${ }^{30}$ Our results suggest one mechanism for Ang IIindependent aldosterone production in VSMCs.

The above findings led us to investigate whether an aldosterone antagonist is able to suppress CS-stimulated NADPH oxidase activity independent of Ang II. Figure 6d clearly shows that eplerenone suppressed the CS-induced activation of NADPH oxidase to a similar extent as ARBs and, furthermore, that co-treatment with eplerenone and ARBs potentiated the suppressive effect. A recent study using an animal model found that eplerenone reduced atherosclerosis by attenuating oxidative stress partially independent of Ang II. ${ }^{31}$ Consistent with this report, our results show the additional effects of eplerenone with ARBs.

Taken together, our data suggest that CS enhances CYP11B2 expression through ERK1/2 phosphorylation dependent on or independent of Ang II and that synthesized aldosterone contributes to ROS generation in the vascular wall (Figure 8). Our data show that aldosterone itself activated ERK1/2 in VSMCs as reported in a recent study. ${ }^{32}$ Furthermore, it has also been reported that aldosterone induces angiotensin-converting enzyme (ACE) gene expression, which is required for Ang II production in cultured rat cardiocytes. ${ }^{33}$ Under conditions with excessive stretch stimuli such as hypertension, 


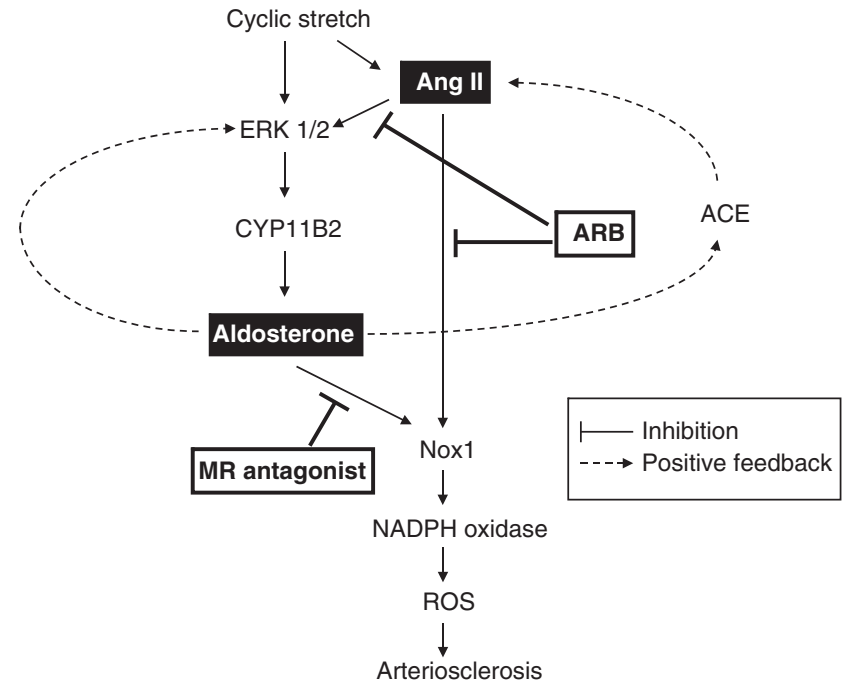

Figure 8 Hypothetic signaling pathway of cyclic stretch-mediated ROS generation through aldosterone.

aldosterone induction in the cardiovascular system may activate these complicated positive feedback loops, resulting in the enhancement of ROS generation and subsequent local vascular wall injury. The suppressive effect of eplerenone on CS-induced NADPH oxidase activation even in the presence of ARBs shown in this study suggests the usefulness of MR antagonists not only in the treatment of high blood pressure but also in the prevention and/or treatment of atherosclerotic complications.

\section{CONFLICT OF INTEREST}

The authors declare no conflict of interest.

\section{ACKNOWLEDGEMENTS}

We are grateful to Tetsuro Ago (Kyushu University) for helpful suggestions. This study was supported by grants from the Ministry of Education, Culture, Sports, Science and Technology, and the Kyushu University Interdisciplinary Programs in Education and Projects in Research Development.

1 Wilson E, Mai Q, Sudhir K, Weiss RH, Ives HE. Mechanical strain induces growth of vascular smooth muscle cells via autocrine action of PDGF. J Cell Biol 1993; 123: 741-747.

2 Wernig F, Mayr M, Xu Q. Mechanical stretch-induced apoptosis in smooth muscle cells is mediated by $\beta 1$-integrin signaling pathways. Hypertension 2003; 42: 903-911.

3 Grote K, Flach I, Luchtefeld M, Akin E, Holland SM, Drexler H, Schieffer B. Mechanical stretch enhances mRNA expression and proenzyme release of matrix metalloproteinase2 (MMP-2) via NAD(P)H oxidase-derived reactive oxygen species. Circ Res 2003; 92 : e80-e86.

4 Inoue N, Kawashima S, Hirata KI, Rikitake Y, Takeshita S, Yamochi W, Akita H, Yokoyama M. Stretch force on vascular smooth muscle cells enhances oxidation of LDL via superoxide production. Am J Physiol 1998; 274: H1928-H1932.

5 Griendling KK, Sorescu D, Ushio-Fukai M. NAD(P)H oxidase: role in cardiovascular biology and disease. Circ Res 2000; 86: 494-501.

6 Hishikawa K, Oemar BS, Yang Z, Luscher TF. Pulsatile stretch stimulates superoxide production and activates nuclear factor-kappa $\mathrm{B}$ in human coronary smooth muscle. Circ Res 1997; 81: 797-803.

7 Griendling KK, Minieri CA, Ollerenshaw JD, Alexander RW. Angiotensin II stimulates NADH and NADPH oxidase activity in cultured vascular smooth muscle cells. Circ Res 1994; 74: 1141-1148.

8 Milliez P, Girerd X, Plouin PF, Blacher J, Safar ME, Mourad JJ. Evidence for an increased rate of cardiovascular events in patients with primary aldosteronism. J Am Coll Cardiol 2005; 45: 1243-1248.
9 Pitt B, Zannad F, Remme WJ, Cody R, Castaigne A, Perez A, Palensky J, Wittes J. The effect of spironolactone on morbidity and mortality in patients with severe heart failure. Randomized Aldactone Evaluation Study Investigators. N Engl J Med 1999; 341: 709-717.

10 Hatakeyama H, Miyamori I, Fujita T, Takeda Y, Takeda R, Yamamoto H. Vascular aldosterone. Biosynthesis and a link to angiotensin II-induced hypertrophy of vascular smooth muscle cells. J Biol Chem 1994; 269: 24316-24320.

11 Callera GE, Montezano AC, Yogi A, Tostes RC, He Y, Schiffrin EL, Touyz RM. C-Srcdependent nongenomic signaling responses to aldosterone are increased in vascular myocytes from spontaneously hypertensive rats. Hypertension 2005; 46: 1032-1038.

12 Callera GE, Touyz RM, Tostes RC, Yogi A, He Y, Malkinson S, Schiffrin EL. Aldosterone activates vascular p38MAP kinase and NADPH oxidase via c-Src. Hypertension 2005; 45: 773-779.

13 Murase K, Naruse K, Kimura A, Okumura K, Hayakawa T, Sokabe M. Protamine augments stretch induced calcium increase in vascular endothelium. Br J Pharmacol 2001; 134: 1403-1410.

14 Ago $T$, Nunoi $H$, Ito T, Sumimoto $H$. Mechanism for phosphorylation-induced activation of the phagocyte NADPH oxidase protein p47(phox). Triple replacement of serines 303, 304 , and 328 with aspartates disrupts the SH3 domain-mediated intramolecular interaction in p47(phox), thereby activating the oxidase. J Biol Chem 1999; 274: 33644-33653.

15 Miwa Y, Sasaguri T, Kosaka C, Taba Y, Ishida A, Abumiya T, Kubohara Y. Differentiationinducing factor-1, a morphogen of dictyostelium, induces G1 arrest and differentiation of vascular smooth muscle cells. Circ Res 2000; 86: 68-75.

16 Gomez-Sanchez EP, Ahmad N, Romero DG, Gomez-Sanchez CE. Origin of aldosterone in the rat heart. Endocrinology 2004; 145: 4796-4802.

17 Norregaard R, Uhrenholt TR, Bistrup C, Skott O, Jensen BL. Stimulation of 11-betahydroxysteroid dehydrogenase type 2 in rat colon but not in kidney by low dietary $\mathrm{NaCl}$ intake. Am J Physiol Renal Physiol 2003; 285: F348-F358.

18 Iwasaki H, Eguchi S, Ueno H, Marumo F, Hirata Y. Mechanical stretch stimulates growth of vascular smooth muscle cells via epidermal growth factor receptor. Am J Physiol Heart Circ Physiol 2000; 278: H521-H529.

19 Wernig F, Mayr M, Xu Q. Mechanical stretch-induced apoptosis in smooth muscle cells is mediated by beta1-integrin signaling pathways. Hypertension 2003; 41: 903-911.

20 Reusch HP, Chan G, Ives HE, Nemenoff RA. Activation of JNK/SAPK and ERK by mechanical strain in vascular smooth muscle cells depends on extracellular matrix composition. Biochem Biophys Res Commun 1997; 237: 239-244.

21 Suzuki J, Otsuka F, Inagaki K, Takeda M, Ogura T, Makino H. Novel action of activin and bone morphogenetic protein in regulating aldosterone production by human adrenocortical cells. Endocrinology 2004; 145: 639-649.

$22 \mathrm{Gu}$ J, Wen Y, Mison A, Nadler JL. 12-lipoxygenase pathway increases aldosterone production, 3',5'-cyclic adenosine monophosphate response element-binding protein phosphorylation, and p38 mitogen-activated protein kinase activation in H295R human adrenocortical cells. Endocrinology 2003; 144: 534-543.

23 Xiao F, Puddefoot JR, Barker S, Vinson GP. Mechanism for aldosterone potentiation of angiotensin II-stimulated rat arterial smooth muscle cell proliferation. Hypertension 2004; 44: 340-345.

24 Griendling KK. Novel NAD(P)H oxidases in the cardiovascular system. Heart 2004; 90 : 491-493. Review.

25 Lassegue B, Sorescu D, Szocs K, Yin Q, Akers M, Zhang Y, Grant SL, Lambeth JD, Griendling KK. Novel gp91(phox) homologues in vascular smooth muscle cells : nox1 mediates angiotensin II-induced superoxide formation and redox-sensitive signaling pathways. Circ Res 2001; 88: 888-894.

26 Sorescu D, Weiss D, Lassègue B, Clempus RE, Szöcs K, Sorescu GP, Valppu L, Quinn MT, Lambeth JD, Vega JD, Taylor WR, Griendling KK. Superoxide production and expression of nox family proteins in human atherosclerosis. Circulation 2002; 105 : $1429-1435$

27 Kalinina N, Agrotis A, Tararak E, Antropova Y, Kanellakis P, Ilyinskaya O, Quinn MT, Smirnov V, Bobik A. Cytochrome b558-dependent NAD(P)H oxidase-phox units in smooth muscle and macrophages of atherosclerotic lesions. Arterioscler Thromb Vasc Biol 2002; 22: 2037-2043.

28 Katsuyama M, Fan C, Yabe-Nishimura C. NADPH oxidase is involved in prostaglandin $\mathrm{F}_{2 \alpha}$-induced hypertrophy of vascular smooth muscle cells: induction of NOX1 by PGF $2 \alpha$. J Biol Chem 2002; 277: 13438-13442.

29 Sato A, Saruta T. Aldosterone escape during angiotensin-converting enzyme inhibitor therapy in essential hypertensive patients with left ventricular hypertrophy. J Int Med Res 2001; 29: 13-21.

30 Tanabe A, Naruse M, Hara Y, Sato A, Tsuchiya K, Nishikawa T, Imaki T, Takano K. Aldosterone antagonist facilitates the cardioprotective effects of angiotensin receptor blockers in hypertensive rats. J Hypertens 2004; 22: 1017-1023.

31 Suzuki J, Iwai M, Mogi M, Oshita A, Yoshii T, Higaki J, Horiuchi M. Eplerenone with valsartan effectively reduces atherosclerotic lesion by attenuation of oxidative stress and inflammation. Arterioscler Thromb Vasc Biol 2006; 26: 917-921.

32 Ishizawa K, Izawa Y, Ito H, Miki C, Miyata K, Fujita Y, Kanematsu Y, Tsuchiya K, Tamaki T, Nishiyama A, Yoshizumi M. Aldosterone stimulates vascular smooth muscle cell proliferation via big mitogen-activated protein kinase 1 activation. Hypertension 2005; 46: 1046-1052.

33 Harada E, Yoshimura M, Yasue H, Nakagawa O, Nakagawa M, Harada M, Mizuno Y, Nakayama M, Shimasaki Y, Ito T, Nakamura S, Kuwahara K, Saito Y, Nakao K, Ogawa H. Aldosterone induces angiotensin-converting-enzyme gene expression in cultured neonatal rat cardiocytes. Circulation 2001; 104: 137-139. 